Supporting Information

\title{
Kinetic Insights into the Mechanism of Oxygen Reduction Reaction on $\mathrm{Fe}_{2} \mathrm{O}_{3} / \mathrm{C}$ composites
}

S. Arya Gopal ${ }^{1}$, Anuroop Edathiparambil Poulose ${ }^{1}$, Chandran Sudakar ${ }^{2}$ and Azhagumuthu Muthukrishnan ${ }^{1, *}$

${ }^{1}$ School of Chemistry, Indian Institute of Science Education and Research

Thiruvananthapuram, Maruthamala (P.O.), Vithura-695551, Kerala, India.

Email:muthukrishnan@iisertvm.ac.in

${ }^{2}$ Multifunctional Materials Laboratory, Department of Physics, Indian Institute of Technology Madras, Chennai -600036, India. 


\section{Chemicals}

Iron nitrate was purchased from Sigma Aldrich, India. Ketjen Black (EC 300J) was received from the Lion Speciality Chemicals Co., Ltd, Japan. Vulcan Carbon X72R was purchased from CABOT India Ltd., India. The graphite powder was purchased from Sigma Aldrich, India.

Table S1. The $\mathrm{Fe}_{2} \mathrm{O}_{3}$ content estimated form XPS peak area and TGA analysis

\begin{tabular}{|c|c|c|}
\hline \multirow[t]{2}{*}{ Compound } & \multicolumn{2}{|l|}{ Wt. $\%$ of $\mathrm{Fe}_{2} \mathrm{O}_{3}$} \\
\hline & $\begin{array}{l}\text { XPS (calculated } \\
\text { from Fe-content) }\end{array}$ & TGA \\
\hline $\mathrm{Fe}_{2} \mathrm{O}_{3} / \mathrm{KB}$ & 1.04 & 30.1 \\
\hline $\mathrm{Fe}_{2} \mathrm{O}_{3} / \mathrm{VC}$ & 1.42 & 29.6 \\
\hline $\mathrm{Fe}_{2} \mathrm{O}_{3} / \mathrm{GO}$ & 10.47 & 56.5 \\
\hline
\end{tabular}




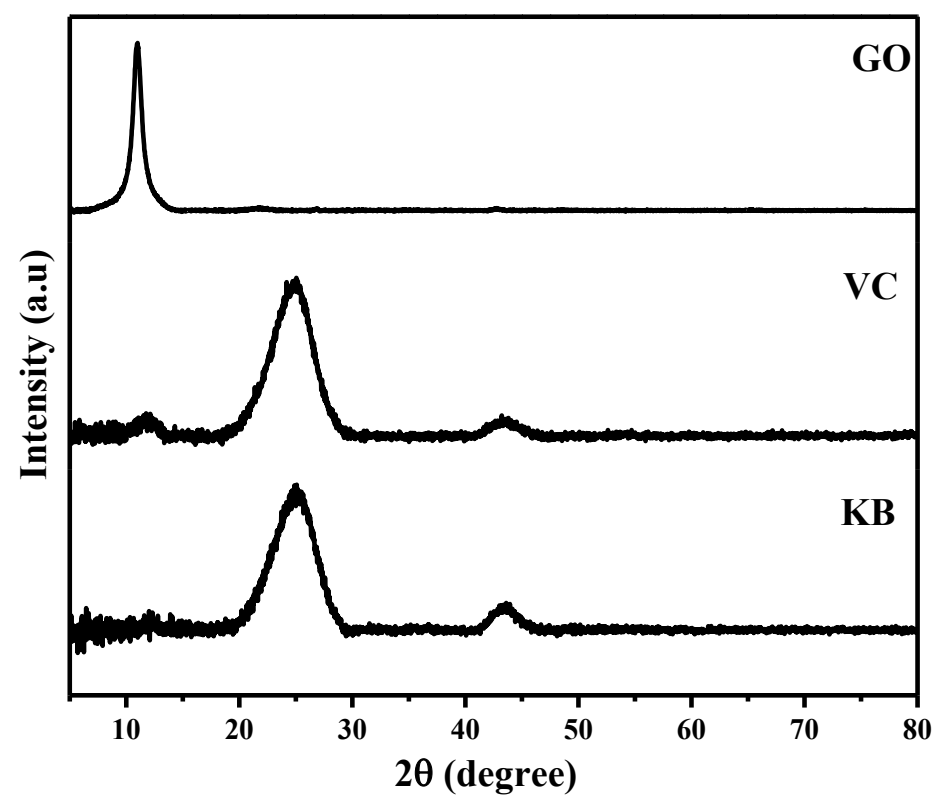

Figure S1. XRD pattern of bare carbon supports
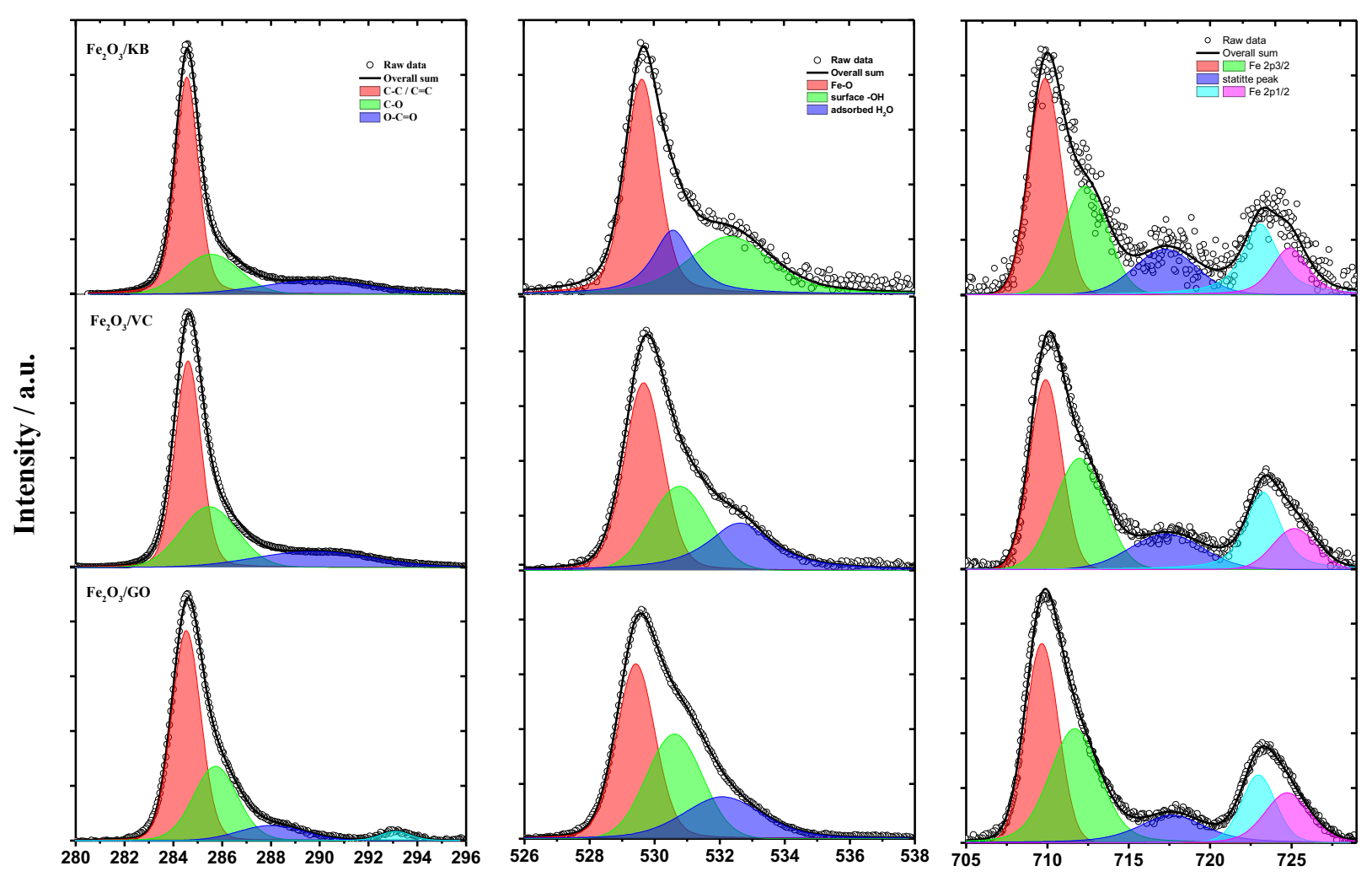

B. E / eV

Figure S2. XPS spectra of the C-1s, O-1s and Fe-2p of the $\mathrm{Fe}_{2} \mathrm{O}_{3} / \mathrm{C}$. Along the row, $1^{\text {st }}$ row: $\mathrm{Fe}_{2} \mathrm{O}_{3} / \mathrm{KB}, 2^{\text {nd }}$ row: $\mathrm{Fe}_{2} \mathrm{O}_{3} / \mathrm{VC}, 3^{\text {rd }}$ row: $\mathrm{Fe}_{2} \mathrm{O}_{3} / \mathrm{GO}$. Along the column, $1^{\text {st }}$ column: $\mathrm{C}-1 \mathrm{~s}$ spectra, $2^{\text {nd }}$ column: O- 1 s spectra, $3^{\text {rd }}$ column: Fe-2p spectra. 


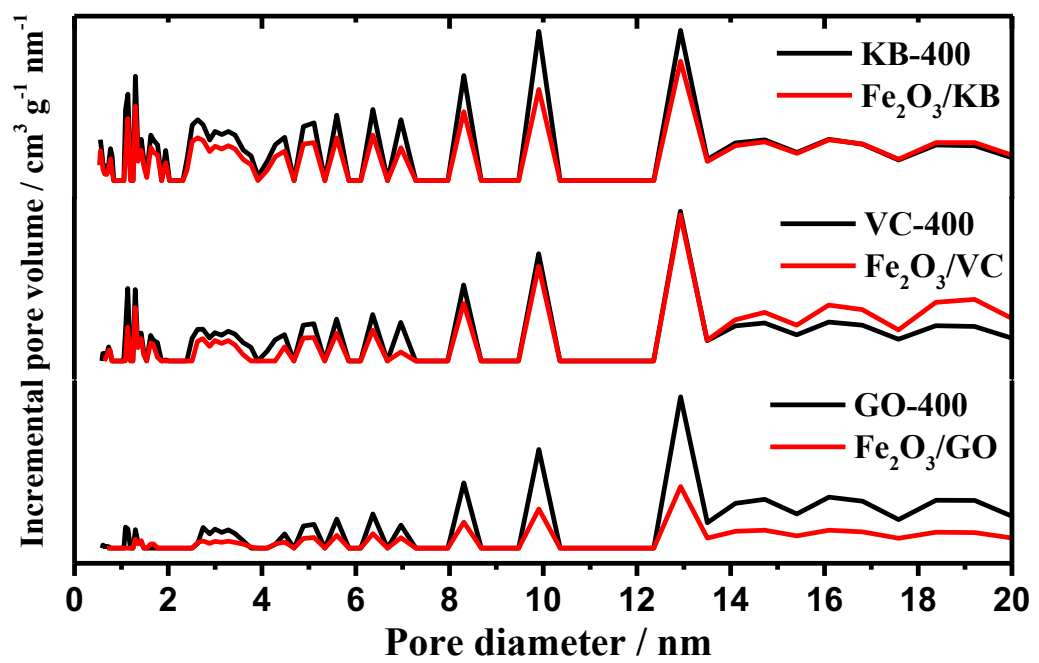

Figure S3. NLDFT pore size distribution curves of $\mathrm{Fe}_{2} \mathrm{O}_{3} / \mathrm{C}$ and bare carbon supports
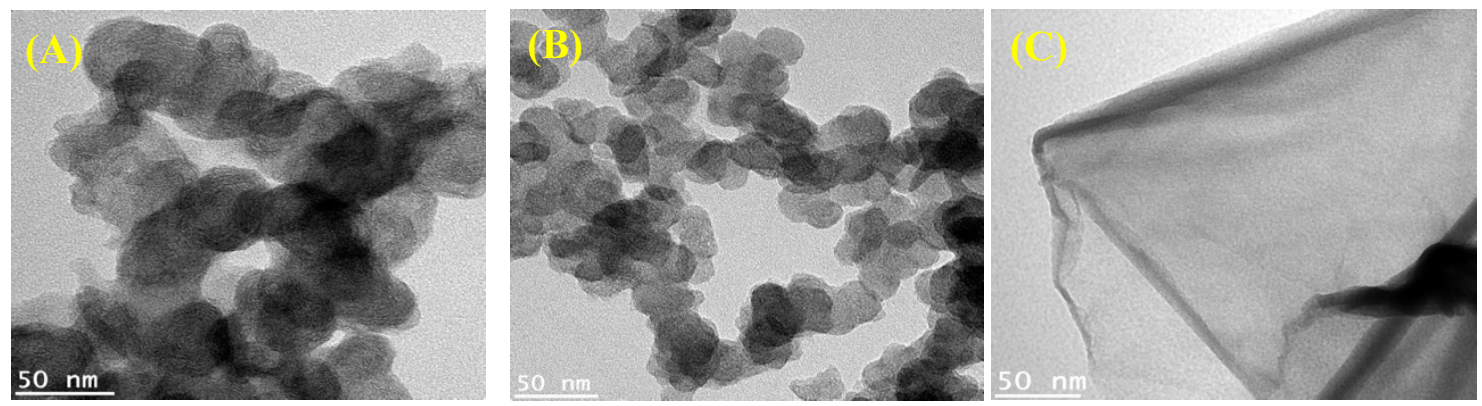

Figure S4. TEM images of the bare carbon supports (A) KB, (B)VC and (C) GO
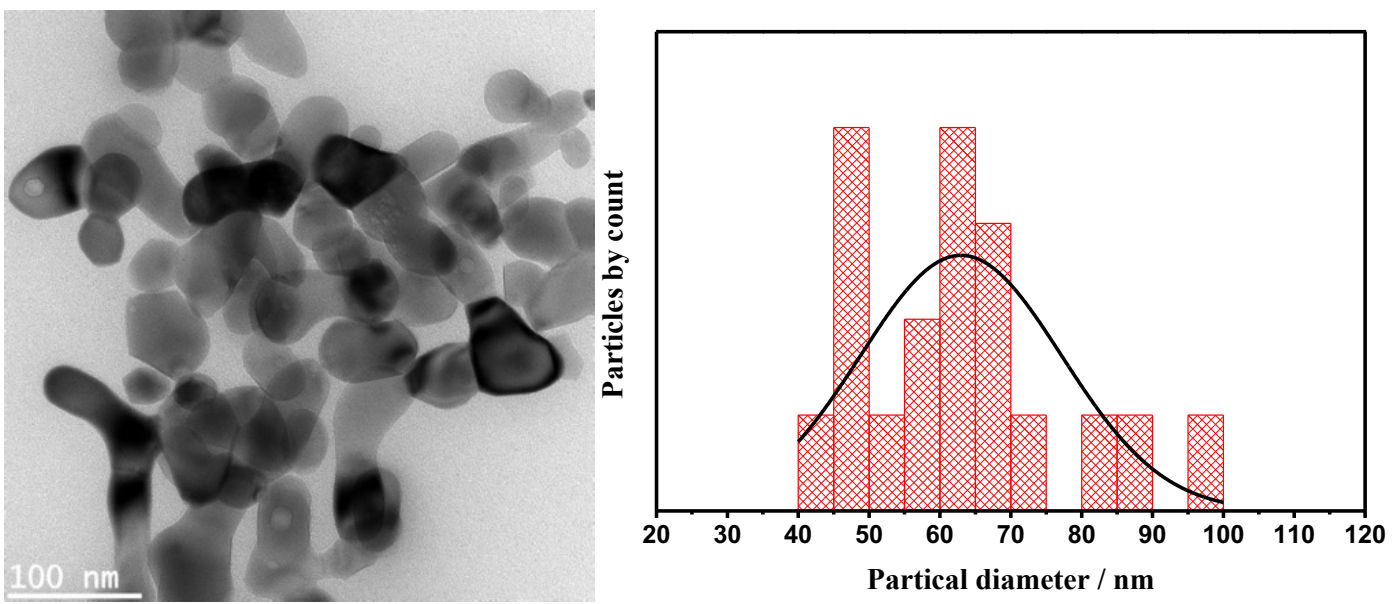

Figure S5. TEM image of $\alpha-\mathrm{Fe}_{2} \mathrm{O}_{3}$ and the particle size distribution histogram 

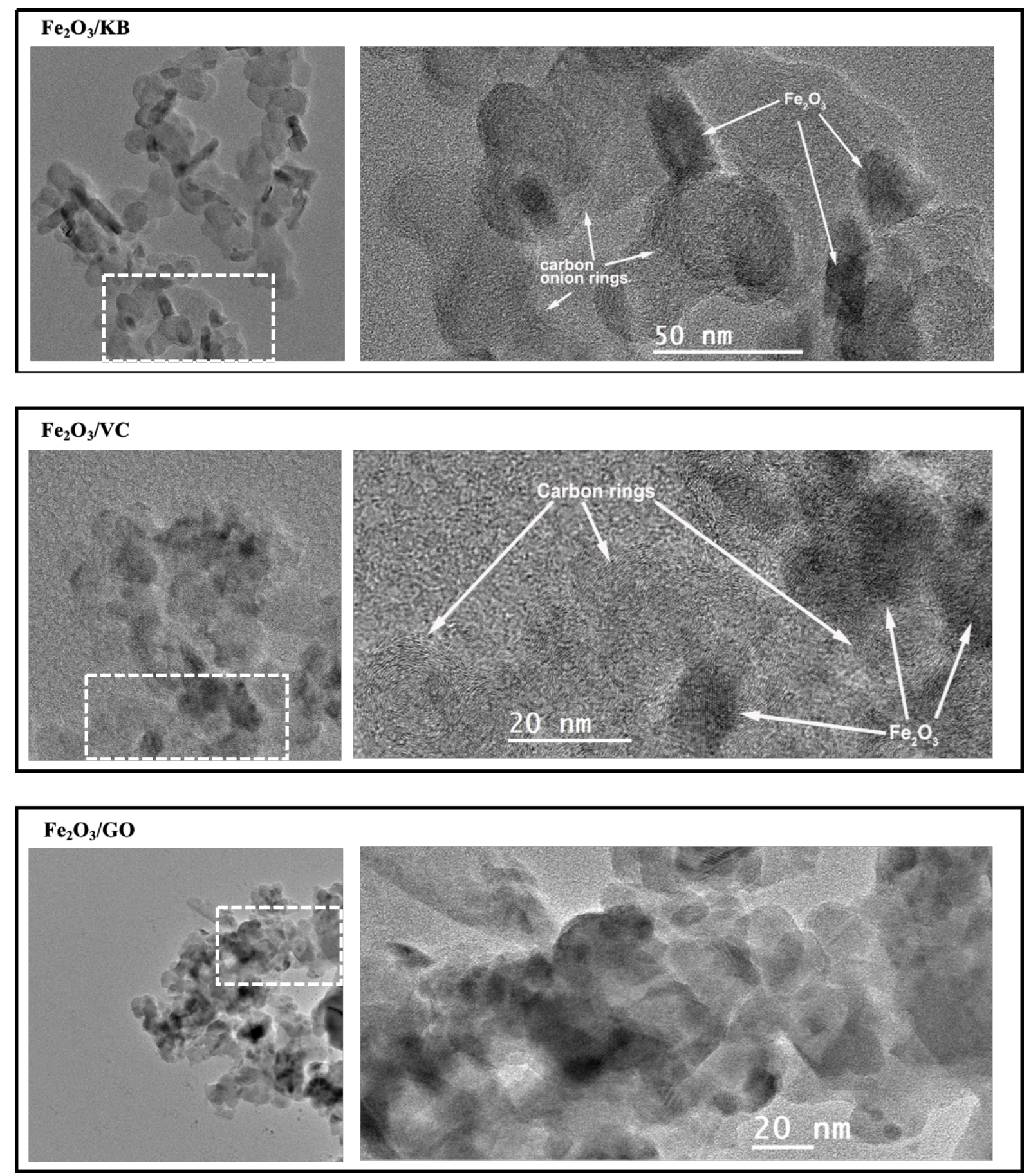

Figure S6. HR TEM images of the $\mathrm{Fe}_{2} \mathrm{O}_{3} / \mathrm{C}$ catalysts, showing the $\mathrm{Fe}_{2} \mathrm{O}_{3}$ nanoparticles embedded in the carbon matrix. 

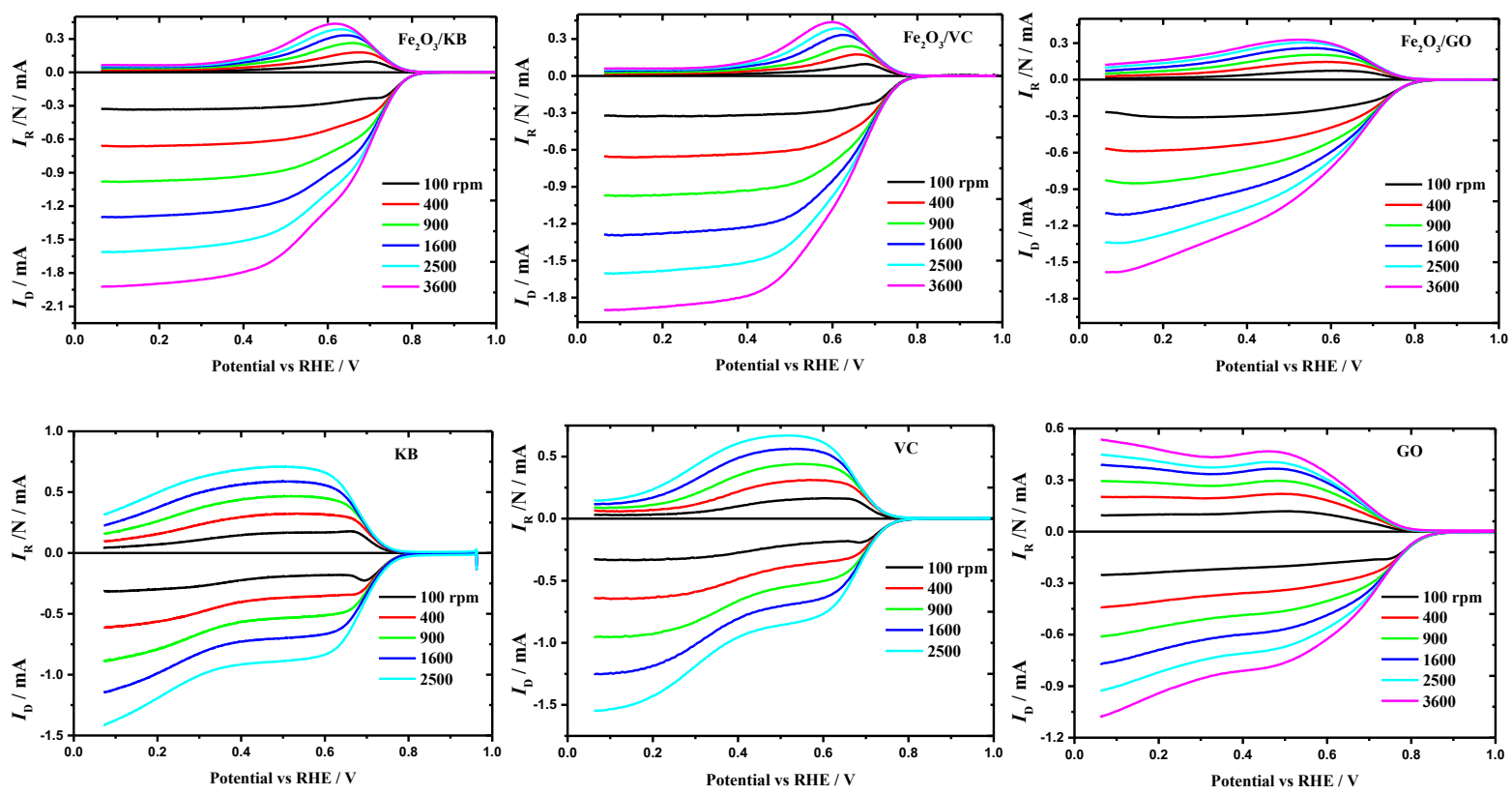

Figure S7. The RRDE voltammograms $\mathrm{Fe}_{2} \mathrm{O}_{3} / \mathrm{C}$ and $\mathrm{Fe}_{2} \mathrm{O}_{3}$-free carbon catalysts coated $\mathrm{GC}$ disk electrode at $\mathrm{O} 2$-saturated $0.1 \mathrm{M} \mathrm{KOH}$ electrolyte solution. Scan rate: $10 \mathrm{mVs}^{-1}$. The platinum ring electrode kept at a constant potential of $1.2 \mathrm{~V}$.

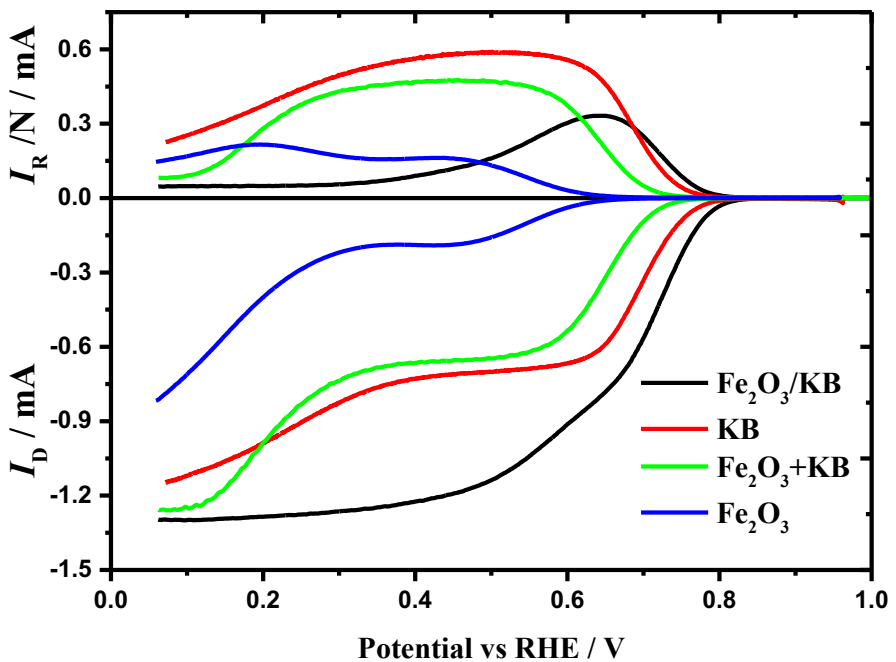

Figure S8. $\mathrm{RRDE}$ voltammograms of the $\mathrm{GC} \mathrm{Fe}_{2} \mathrm{O}_{3} / \mathrm{KB}$ compared with the $\mathrm{KB}, \mathrm{Fe}_{2} \mathrm{O}_{3}+\mathrm{KB}$ physical mixture and $\mathrm{Fe}_{2} \mathrm{O}_{3}$ at $\mathrm{O}_{2}$-saturated $0.1 \mathrm{M} \mathrm{KOH}$ solution. The scan rate for the linear sweep voltammetry is $10 \mathrm{mV} \mathrm{s}^{-1}$, and the electrode is rotated at $1600 \mathrm{rpm}$. 


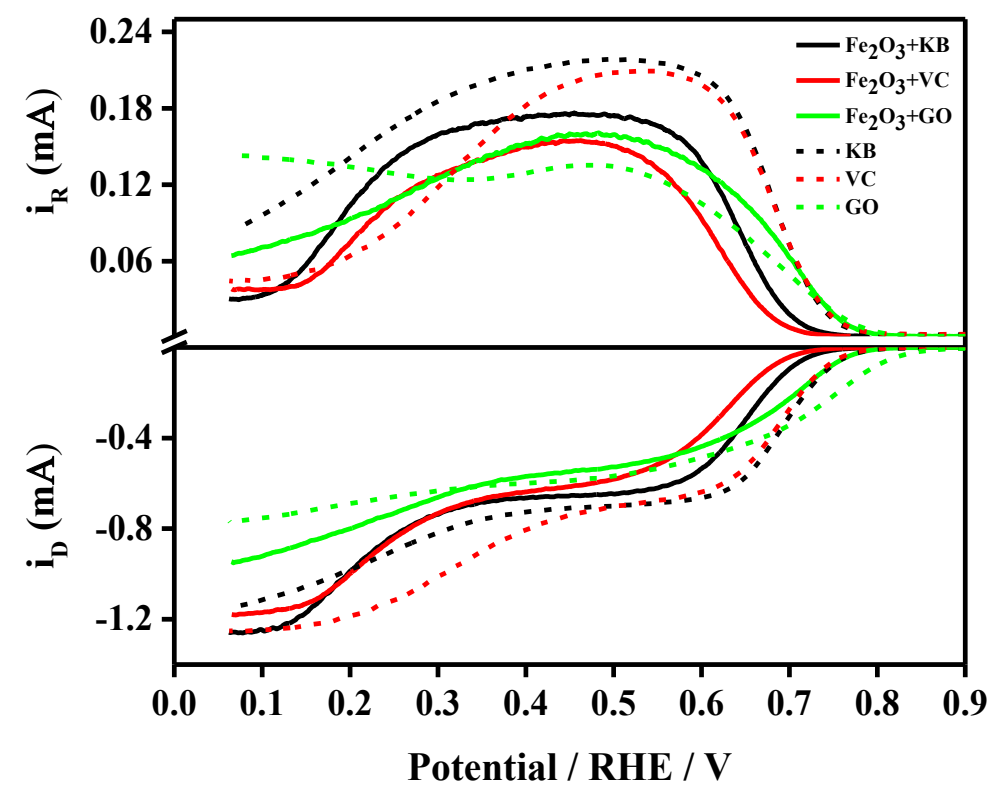

Figure S9. RRDE voltammograms of the physical mixtures $\mathrm{Fe}_{2} \mathrm{O}_{3}+\mathrm{KB}, \mathrm{Fe}_{2} \mathrm{O}_{3}+\mathrm{VC}$, $\mathrm{Fe}_{2} \mathrm{O}_{3}+\mathrm{GO}$ compared with the bare carbon supports at $\mathrm{O}_{2}$-saturated $0.1 \mathrm{M} \mathrm{KOH}$ solution. The scan rate for the linear sweep voltammetry is $10 \mathrm{mVs}^{-1}$, and the electrode is rotated at 1600 rpm. 

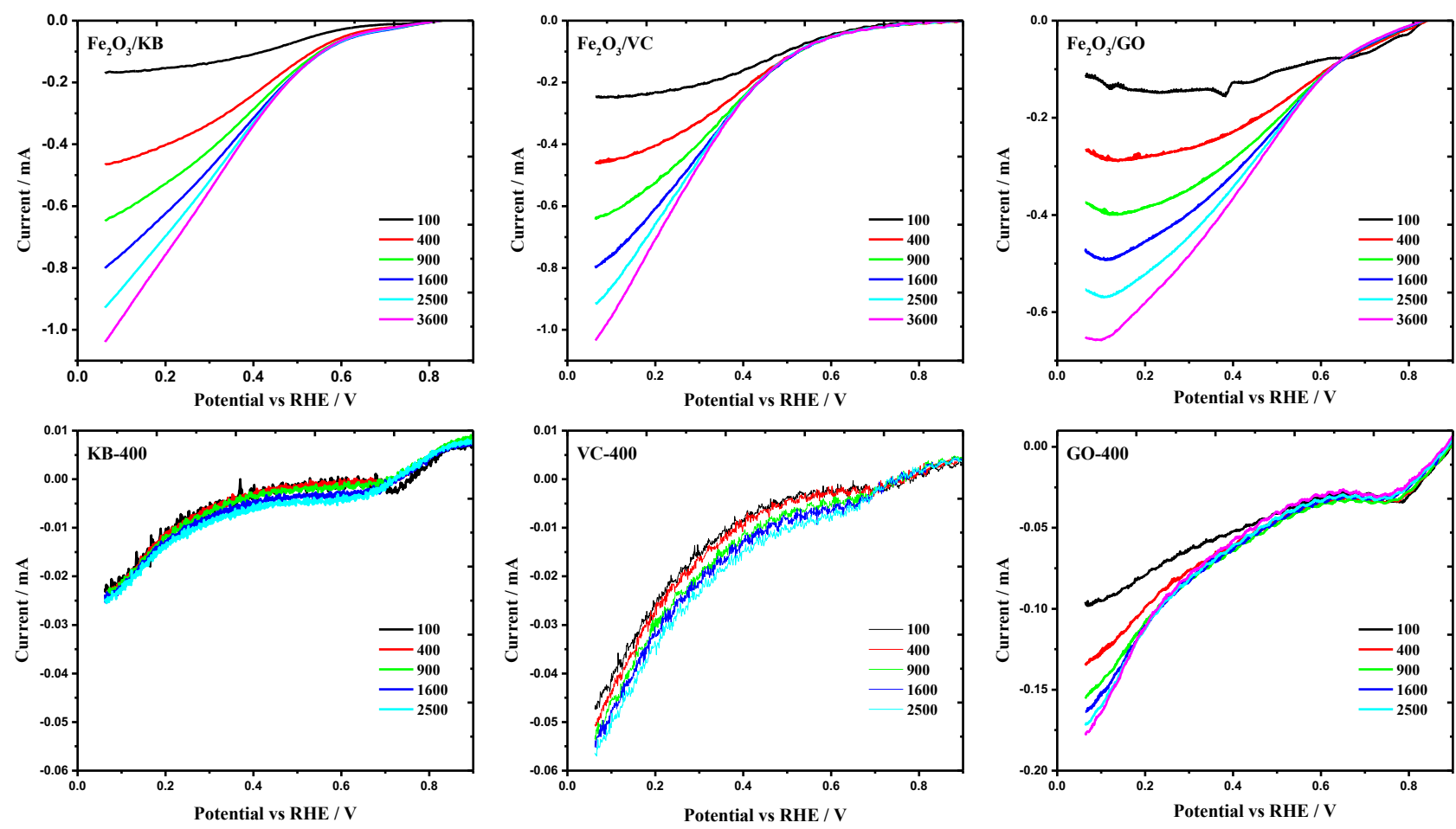

Figure S10. RDE voltammograms of $\mathrm{H}_{2} \mathrm{O}_{2}$ reduction reaction on $\mathrm{Fe}_{2} \mathrm{O}_{3} / \mathrm{C}$ and carbon substrates in $0.1 \mathrm{M} \mathrm{KOH}$ solution. The concentration of $\mathrm{H}_{2} \mathrm{O}_{2}$ is $2 \mathrm{mM}$. The scan rate is 10 $\mathrm{mVs}^{-1}$.
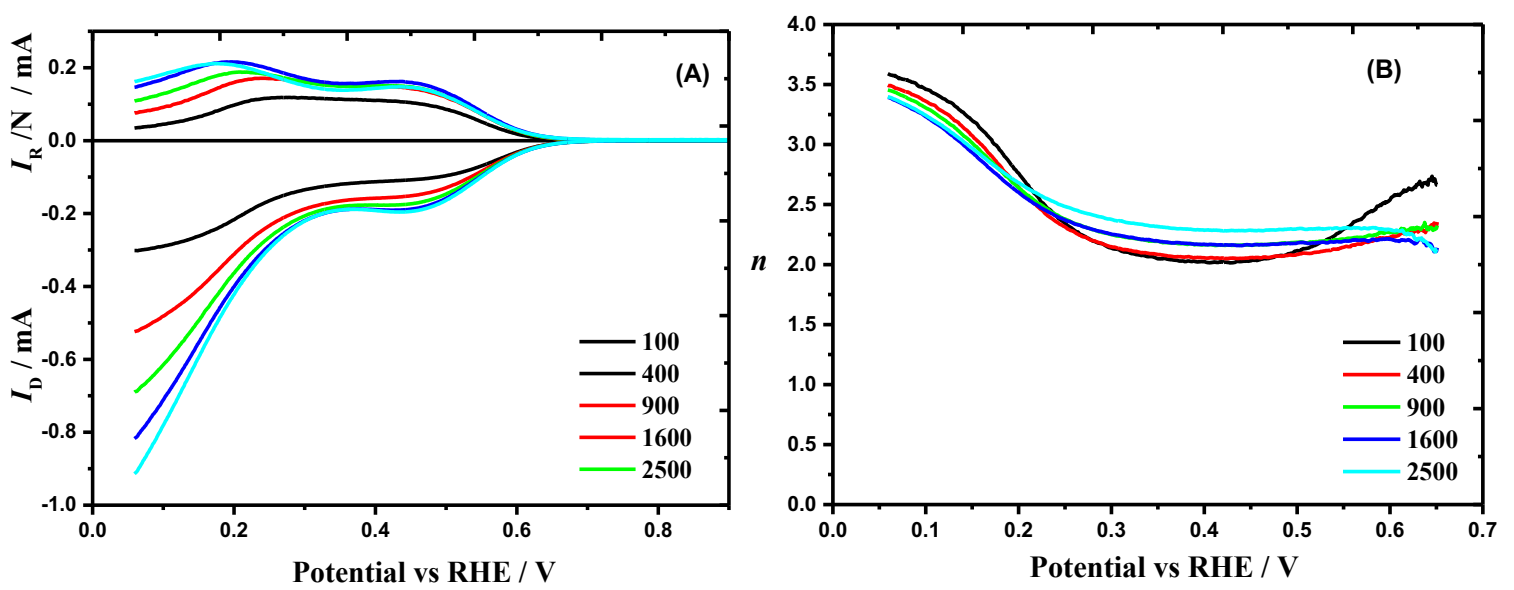

Figure S11. (A) The RRDE voltammograms for the ORR on $\alpha-\mathrm{Fe}_{2} \mathrm{O}_{3}$ in $0.1 \mathrm{M} \mathrm{KOH}$ electrolyte and (B) the number of electrons at various rotational speed. 

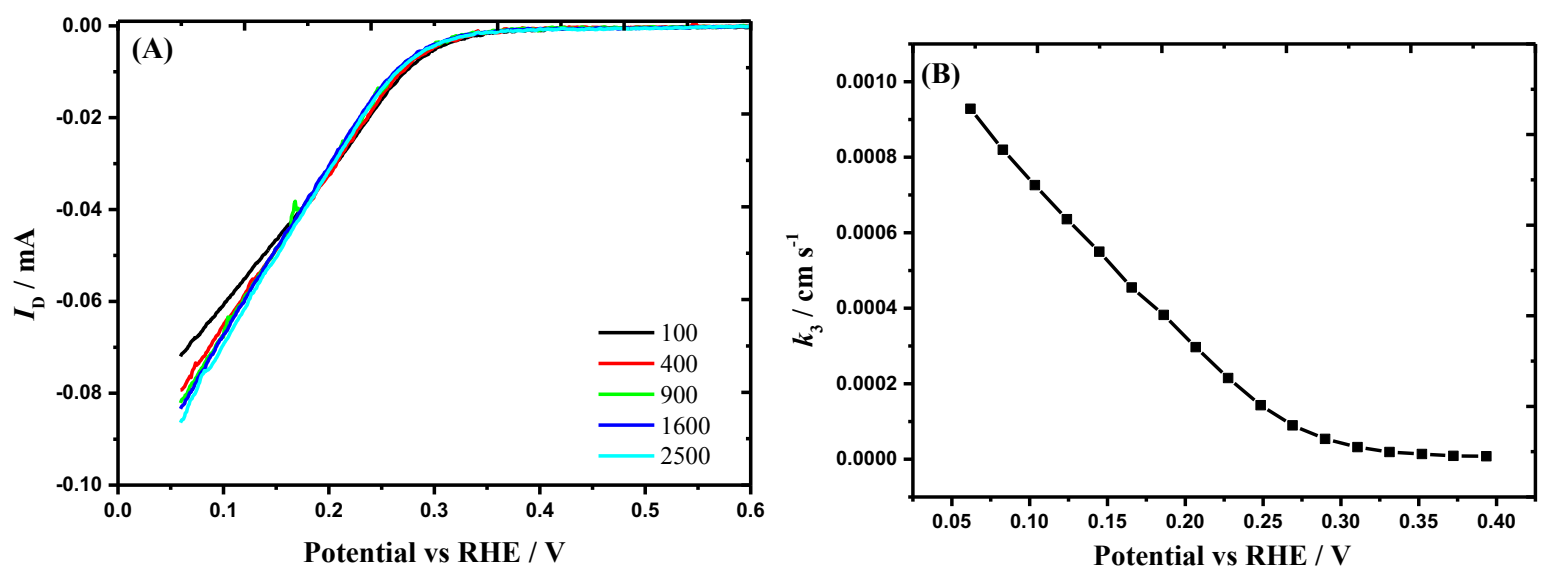

Figure S12. RDE voltammogram of the HPRR on the $\alpha-\mathrm{Fe}_{2} \mathrm{O}_{3}$ modified GC disk electrode in $0.1 \mathrm{M} \mathrm{KOH}$, and (B) the potential-dependent rate constants estimated using the kinetic currents from the K-L plot.

\section{THEORETICAL CALCULATIONS}

The ORR, HPRR and HP formation were studied on a-Fe $\mathrm{O}_{3}(0001)$ surface using spinpolarized plane-wave density functional theory as implemented in the QUANTUM ESPRESSO package. The Perdew, Burke, and Ernzerhof (PBE) $)^{1}$ GGA exchange-correlation functional and projected augmented wave (PAW) potentials were employed..$^{2-4}$ The DFT+U formalism $^{5}$ was used to account for the strongly correlated nature of the localized $3 \mathrm{~d}$ electrons in $\mathrm{Fe}_{2} \mathrm{O}_{3}$. An effective Hubbard-U parameter was introduced with $U=4 \mathrm{eV}$. A kinetic energy cut-off of 50 Ry for the wave function and 300 Ry for the charge density was used for all calculations. The van der Waals interactions were considered using D3 dispersion by Grimme et al. ${ }^{6}$ The $4 \times 4 \times 1$ Monkhorst- Pack $^{7}$ k-point sampling was used for selfconsistent calculations.

The a-Fe $\mathrm{O}_{3}$ (0001) surface was modelled from calculated lattice parameters of the bulk 30 atom hexagonal unit cell containing six formula units (using 4 x 4 x 4 k-point grid). Antiferromagnetic arrangement $(\uparrow \downarrow \downarrow \uparrow)^{8}$ was chosen for Fe atom layers identified as the most stable spin configuration for $\mathrm{Fe}_{2} \mathrm{O}_{3}$. Calculated lattice constants $a=b=5.10 \AA$ and 
$c=13.92 \AA$ were in agreement with previously reported figures. ${ }^{9-10}$ The magnetic moment per Fe atom was estimated as $4.1 \mu_{\mathrm{B}}$, and a bandgap of about $2.0 \mathrm{eV}$ was obtained. The Fe terminated slab was modelled using a $2 \times 2$ supercell with $\sim 18 \AA$ vacuum in the $z$-direction. The supercell contains 80 atoms with $4 \mathrm{Fe}_{2} \mathrm{O}_{3}$ layers, 20 atoms in each layer $(8 \mathrm{Fe}$ and $12 \mathrm{O}$ atoms). All atoms were relaxed until the forces reached below $0.005 \mathrm{eV} \AA^{-1}$ per atom.

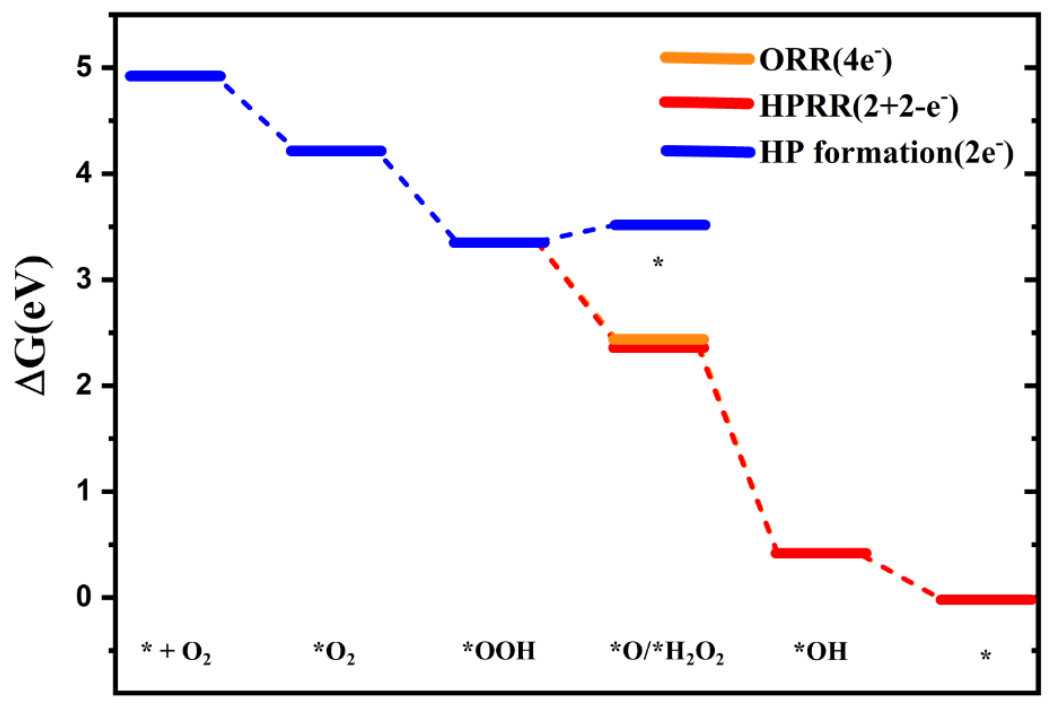

Reaction coordinate

Figure S13. Comparison of the free energy profile of the 4-electron, 2+2-electron and the formation of the $\mathrm{OOH}^{-}$at $0 \mathrm{~V}$. 
(A)
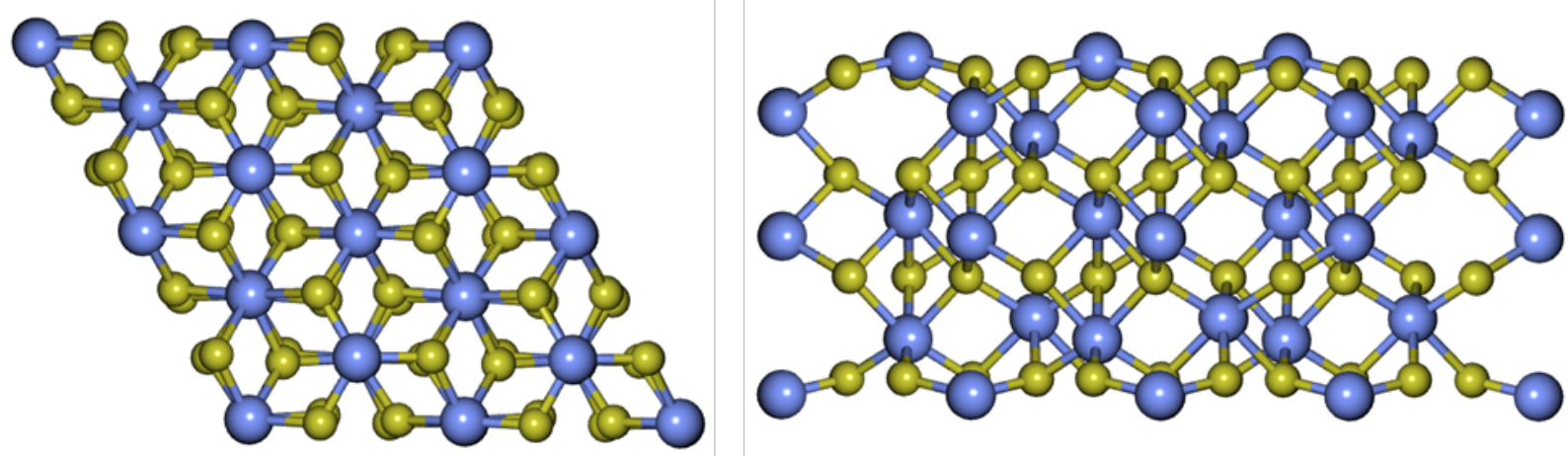

(B)
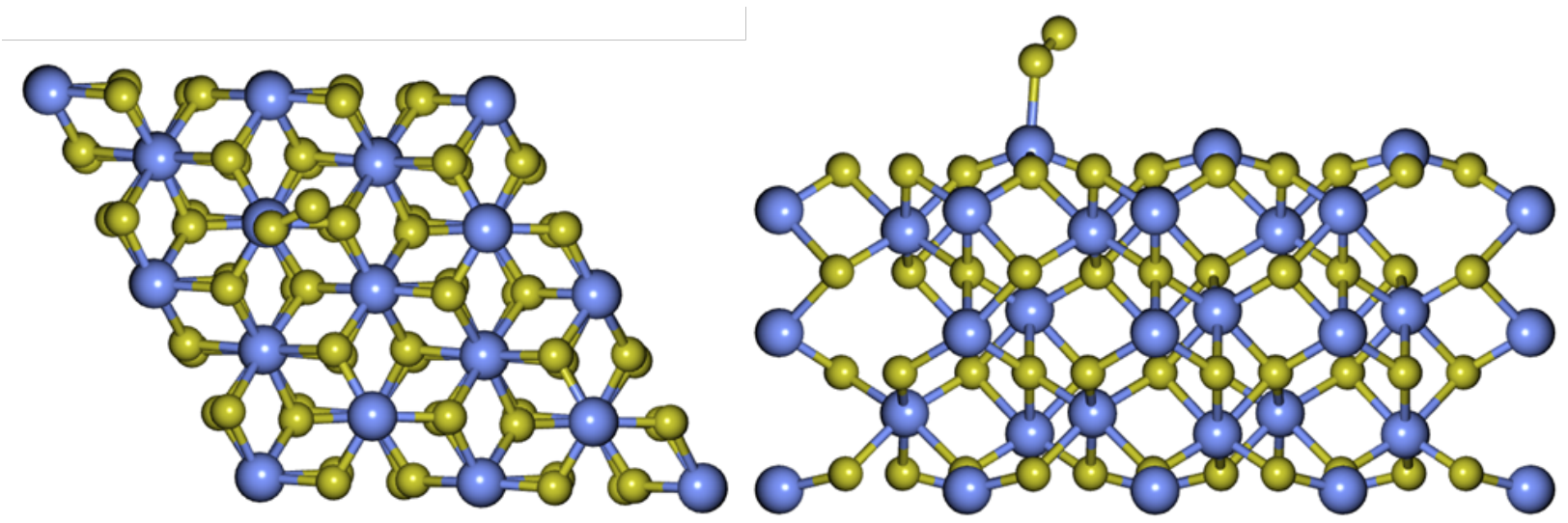

(C)
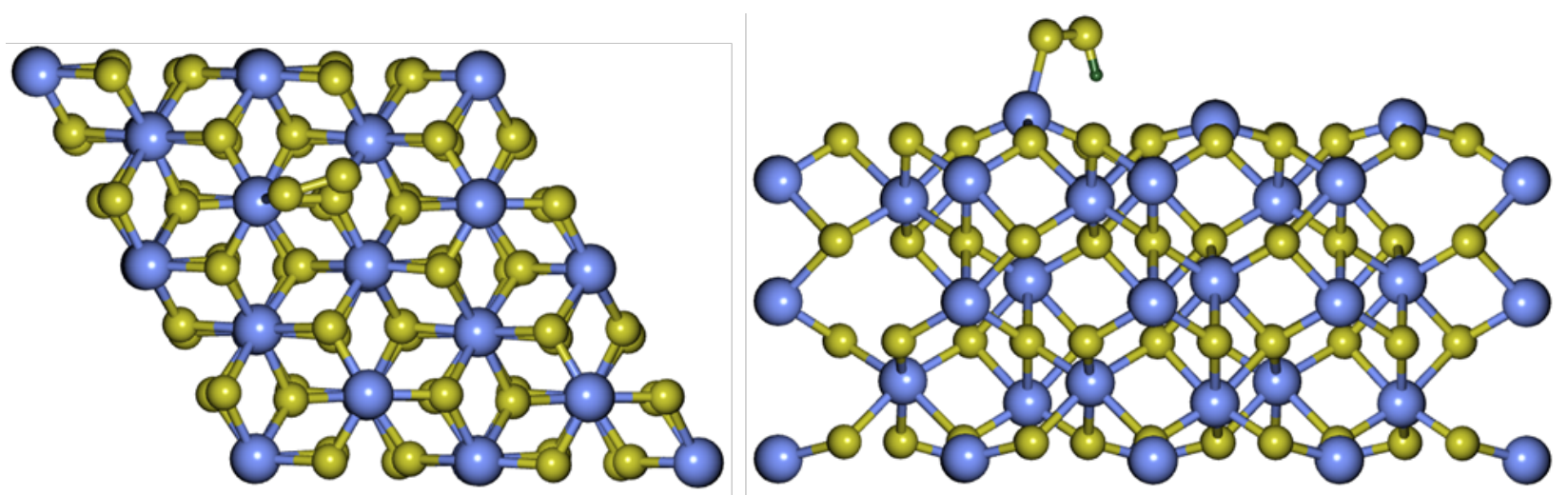
(D)
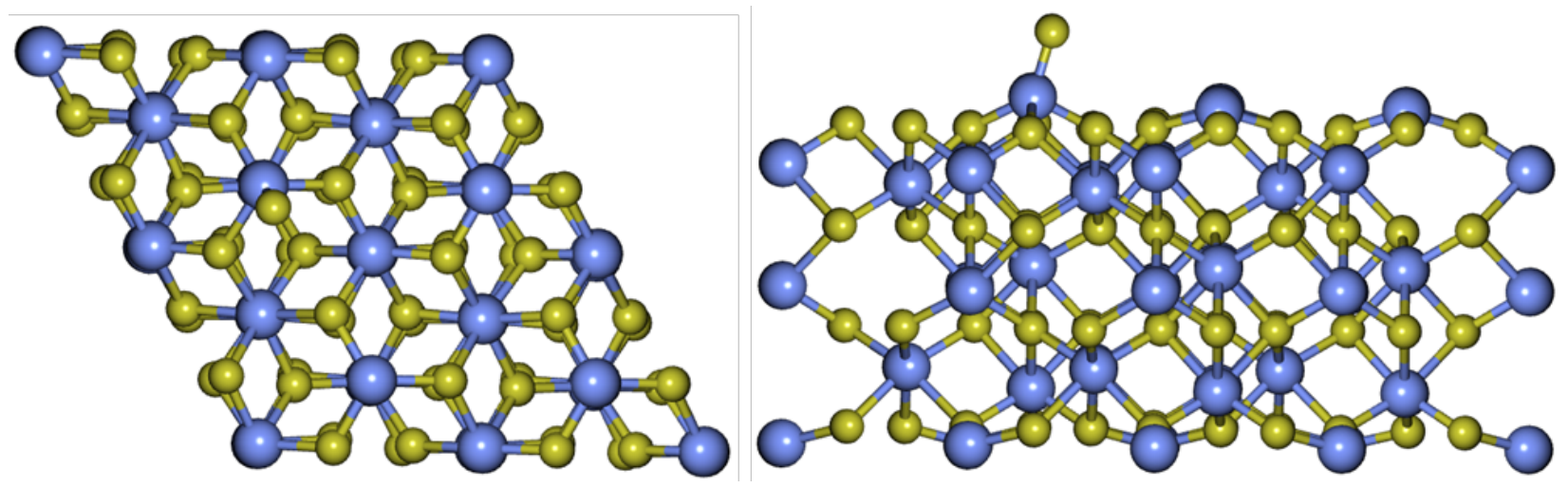

(E)
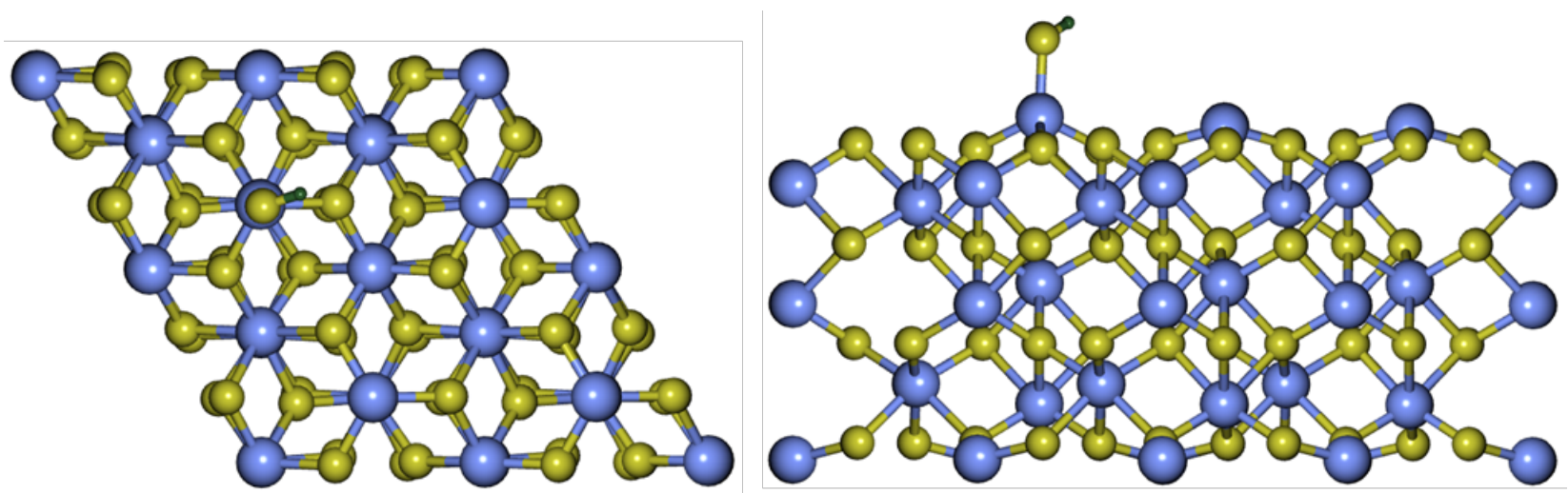

(F)
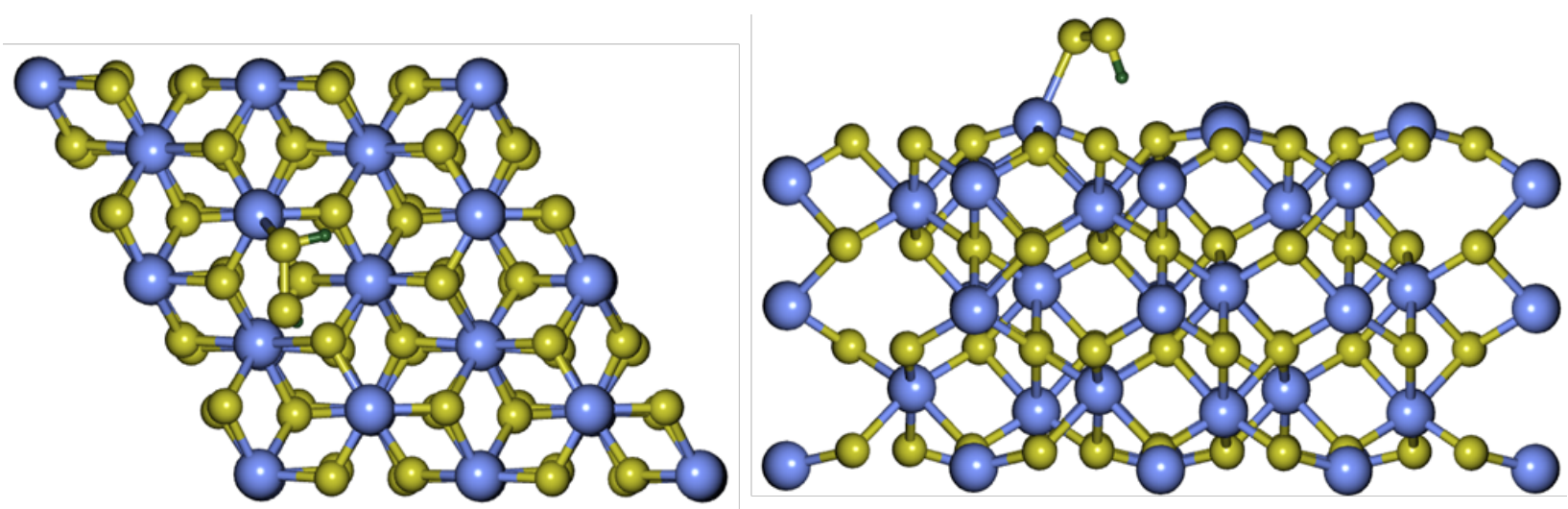

Figure S14. Top and sides views of a-Fe $\mathrm{O}_{3}(0001)$ surface (A) pure a-Fe $\mathrm{O}_{2} \mathrm{O}_{3}(0001)$ (B) $\mathrm{O}_{2}$ adsorbed, (C) $\mathrm{OOH}$ adsorbed, (D) $\mathrm{O}$ adsorbed, (E) $\mathrm{OH}$ adsorbed and (F) $\mathrm{H}_{2} \mathrm{O}_{2}$ adsorbed 


\section{REFERENCES}

(1) Perdew, J. P.; Burke, K.; Ernzerhof, M. Generalized Gradient Approximation Made Simple. Phys. Rev. Lett. 1996, 77 (18), 3865-3868.

(2) Blöchl, P. E. Projector augmented-wave method. Phys. Rev. B 1994, 50 (24), 1795317979.

(3) Kresse, G.; Joubert, D. From ultrasoft pseudopotentials to the projector augmented-wave method. Phys. Rev. B 1999, 59 (3), 1758-1775.

(4) Dal Corso, A. Pseudopotentials periodic table: From H to Pu. Comp. Mater. Sci. 2014, 95, 337-350.

(5) Anisimov, V. I.; Aryasetiawan, F.; Lichtenstein, A. I. First-principles calculations of the electronic structure and spectra of strongly correlated systems: the LDA+Umethod. J. Phys. Condens. Matter 1997, 9 (4), 767-808.

(6) Grimme, S.; Antony, J.; Ehrlich, S.; Krieg, H. A consistent and accurate ab initio parametrization of density functional dispersion correction (DFT-D) for the 94 elements HPu. J. Chem. Phys. 2010, 132 (15), 154104.

(7) Monkhorst, H. J.; Pack, J. D. Special points for Brillouin-zone integrations. Phys. Rev. B 1976, $13(12), 5188$.

(8) Pozun, Z. D.; Henkelman, G. Hybrid density functional theory band structure engineering in hematite. J. Chem. Phys. 2011, 134 (22), 224706.

(9) Huang, X.; Ramadugu, S. K.; Mason, S. E. Surface-specific DFT+ U approach applied to $\alpha-\mathrm{Fe}_{2} \mathrm{O}_{3}(0001) . J$. Phys. Chem. C 2016, 120 (9), 4919-4930.

(10) Liao, P.; Keith, J. A.; Carter, E. A. Water oxidation on pure and doped hematite (0001) surfaces: Prediction of $\mathrm{Co}$ and $\mathrm{Ni}$ as effective dopants for electrocatalysis. J. Am. Chem. Soc. 2012, 134 (32), 13296-13309. 